\title{
Host Plant Growth Form and Diversity: Effects on Abundance and Feeding Preference of a Specialist Herbivore, Acalymma vittata (Coleoptera: Chrysomelidae)
}

\author{
Catherine E. Bach \\ Division of Biological Sciences, University of Michigan, Ann Arbor, MI 48109 USA
}

\begin{abstract}
Summary. Abundances of the specialist herbivore, Acalymma vittata (Fab.) (Coleoptera: Chrysomelidae), were assessed in small experimental plots with three levels of plant diversity (cucumber monoculture, cucumber/corn, and cucumber/tomato) and two levels of host plant growth form (horizontal on the ground and vertical, staked up or growing up other plant species). Host plant growth form more strongly affected beetle abundances than did plant diversity; greater numbers were found on vertically growing than on horizontally growing cucumber plants. The combination of cucumber monoculture and vertical growth form supported significantly greater herbivore abundances than did any other type of plot, emphasizing a strong interaction between diversity and growth form. Beetles were not more common in monocultures with horizontal growth forms than in mixed species plots, and beetles did not respond differently to plots with corn and plots with tomatoes.

Feeding experiments demonstrated that the plant diversity under which a host plant is grown strongly influenced herbivore feeding preference. Beetles given a choice of cucumber leaves grown in monoculture and in plots with tomatoes exhibited individual differences in their food selection behavior, however, a significantly greater number of beetles preferred monoculture leaves. Those individuals preferring monoculture leaves and those individuals preferring leaves from plots with tomatoes did not differ in either absolute or relative amounts of feeding damage per leaf.

Neither plant size nor the date on which plots were colonized by beetles explained the differences in herbivore abundance. It is suggested that differences in movement patterns and plant quality contributed to the greater numbers of beetles on plants growing vertically in monocultures.
\end{abstract}

\section{Introduction}

Effects of plant diversity on herbivore abundances have been documented for agricultural (Tahvanainen and Root 1972, Root 1973, Risch 1979, Bach 1980a, 1980 b) as well as natural plant communities (Murdoch et al. 1972, Smith and Whittaker 1980a, 1980 b). Specialist herbivores often have greater population densities (Root 1973, Altieri et al. 1978, Bach 1980a, 1980 b), reproduction (Tahvanainen and Root 1972, Altieri et al. 1977), and colonization (van Emden 1965, Dempster and Coaker 1974) in monocultures of their host plant than in polycultures containing additional plant species. Although the decrease in population densities associated with increased plant diversity is well documented for a wide range of herbivore species, including Coleoptera, Homoptera, and Lepidoptera, only recently have studies begun to elucidate the mechanisms contributing to this decrease (Bach 1980a, 1980b, Smith and Whittaker 1980b).

There is evidence that herbivores remain for longer periods of time in monocultures of their host plant than in habitats containing additional plant species and it has been suggested that this may be a result of differences in plant quality (Bach $1980 \mathrm{a}, 1980 \mathrm{~b}$ ). Plant density has been shown to influence plant quality, in terms of amino acid and fiber content (Fagan et al. 1943), and a link between increased plant density and reduced nutritional value of the host plant has been suggested (Way and Heathcote 1966). Few studies have documented effects of plant diversity on plant quality, although Winter (1961) suggested that plants may acquire chemicals from the roots of other plant species with which they are grown, resulting in a modification of the nutritional value of the plant for herbivores. Certain aspects of plant quality (e.g., levels of leaf nitrogen) have been found recently to influence strongly herbivore feeding (Slansky and Feeny 1977, McNeill and Southwood 1978, Cates 1980, Mattson 1980, Morrow and Fox 1980). Even though studies have compared herbivore feeding, development, and fecundity on different species of host plants (Hsiao and Fraenkel 1968, Scriber and Feeny 1979, Brown et al. 1980, Chew 1980) and on different parts of the same host plant (Ralph 1976), no study has compared feeding preferences by herbivores for the same host plant grown under different plant diversities.

In addition to effects on plant quality, the diversity of the habitat in which plants are growing would also be expected to affect plant growth form. Thus, it becomes important to determine effects of host plant growth form on herbivore abundance. Lawton (1978) provides evidence for a "plant architecture" hypothesis explaining differences in species diversity of herbivores, but studies examining effects of host plant growth form have only compared herbivore populations on different species of host plants with different growth forms (Scriber and Feeny 1979), not on the same species with different growth forms. Moreover, few studies have tried to separate structural from biological (i.e., chemical) effects of the presence of additional plant species in polycultures. One way to do this would be to look at the response of an herbivore species to (1) habitats with different plant structures, but without biological differences (i.e., different host plant growth forms), and (2) diverse habitats containing different plant species (thus different structures).

This study examined the following three questions: (1) Does host plant growth form (whether the host plant is growing horizontally on the ground versus vertically) influence herbivore abundance?, (2) Are herbivore abundances different when their host plant is grown with different non-host plant species?, and (3) Are feeding preferences of herbivores affected by the plant 
diversity under which their host plant is grown? I studied the striped cucumber beetle, Acalymma vittata (Fab.) (see Bach 1980a, 1980b, for a description of the natural history of this species) on its host plant, cucumber (Cucumis sativus L.), because of the information already known about the interaction between plant spatial pattern and the population dynamics of this specialist herbivore (Bach 1980a, 1980 b).

\section{Materials and Methods}

\section{Experimental Plots}

Experimental plots were located in an agricultural field at the Matthaei Botanical Gardens (University of Michigan, Washtenaw County, MI) in 1980. Cucumbers (Cucumis sativus L.) were grown in monoculture (C) and in combination with either corn (CC, Zea mays L.) or tomatoes (CT, Lycopersicon esculentum Mill.). For each of these three species compositions, cucumbers were either grown on the ground $(\mathrm{H}$, horizontal growth form) or vertically (V), staked up in monocultures and growing up the other plant species in the plots with corn or tomatoes. These six treatments were randomized in each of four blocks, arranged linearly $(5 \mathrm{~m}$ from larger experimental plots containing cucumbers, corn, and tomatoes) with $1.5 \mathrm{~m}$ between plots. Each plot was $1 \mathrm{~m}$ by $0.5 \mathrm{~m}$ and contained four cucumber plants plus four additional plants in those plots which contained corn or tomatoes. Plots contained two rows of four plants each, planted in an alternating pattern with cucumbers in positions 1 and 3 of one row and positions 2 and 4 of the other row, and the additional plant species (in the case of corn and tomato plots) or no plants (in the case of monocultures) in the remaining positions. Rows were perpendicular to the line of twenty-four plots and were in a north-south direction.

The herbicide Roundup and the pesticide Diazinon were applied on 23 May and 27 May, respectively. Cucumber and corn seeds were planted on 19 July and plants were thinned to one per location on 5 August. Tomato seedlings (between 5 and $10 \mathrm{~cm}$ tall) were transplanted on 22 July. On 29 July a $0.5 \mathrm{~m}$ strip around the exterior of each plot was mulched with grass clippings. Weeds within the plots were hand pulled, whereas ground between plots was periodically hoed to prevent weeds from shading the plots. Plants in plots receiving the treatment of vertical growth form were staked up or wound around the additional plant species on 23 August. However, the slower growth of cucumbers when grown with corn prevented their attaining a vertical growth form until 2 September.

\section{Sampling Methods}

The number of individuals of $A$. vittata on all cucumber plants was sampled on each of 16 days between 12 August and 22 September, corresponding to between 24 and 65 days after planting. Direct observation was utilized because it is the most accurate method for this species (Chiang and Flaskerd 1965) and has been used in related studies (Bach 1980a, 1980 b). On each sampling date, all leaves, flowers and stems were searched for beetles.

Cucumber plant size was measured on 23 September, after the last beetle sampling had been completed. The length of all vines of each plant was measured. This method provides rapid, accurate measurements of plant size and correlates very significantly with both the number of leaves and leaf area (Bach 1981).

Data were analyzed with a three-way fixed-effects model analysis of variance (ANOVA), testing for significant effects of plot diversity (3 levels), plant growth form ( 2 levels), an interaction between growth form and diversity, and block (position in field). Individual comparisons between the six types of treatments were tested with the Scheffe procedure for multiple comparison, at a 0.9 significance level (see Bach 1980 b for detailed discussion of statistical methods).

\section{Feeding Experiments}

On each of three dates $(11,17$, and 22 September), twenty individuals of $A$. vittata were collected in the experimental plots, brought back to the laboratory and each beetle placed in a separate cage $(25 \mathrm{~cm}$ high $\times 25 \mathrm{~cm} \times 25 \mathrm{~cm}$, made of mesh cloth on a wooden frame). A vial containing water, two cucumber leaves (picked three hours earlier), and cotton, was placed in each cage; one leaf was from a cucumber monoculture plot with vertical growth form and the other leaf was from a cucumber and tomato plot with vertical growth form. Five undamaged leaves were picked from each of the four replicates of each type of treatment. Leaf size and position in the vial were controlled.

The amount of feeding damage after $72 \mathrm{~h}$ (measured to the nearest $0.25 \mathrm{~cm}^{2}$ removed) was recorded. Because feeding damage data did not satisfy the assumption of normality, non-parametric statistical tests (sign test and Mann-Whitney $U$ test) were utilized for data analysis.

\section{Results}

\section{Herbivore Abundances}

The number of beetles found in the plots increased throughout the season, with total numbers sampled in all plots varying from 1 to 6 for sampling dates in August $(N=9)$ and from 12 to 60 for sampling dates in September $(N=7)$. This increase was caused by the late summer/early fall emergence of new generation beetles (see Bach $1980 \mathrm{~b}$ for detailed study of the population dynamics of this species). Distinct differences in the number of beetles in the six types of plots are apparent, with $51 \%$ of the 321 total beetles recorded throughout the season being found in one treatment, cucumber monocultures with vertical growth form $(\mathrm{C}-\mathrm{V})$. These differences demonstrate that beetles do distinguish between different treatments even in extremely small plots. Beetles were much more commonly found in closed flowers $(65 \%)$ than on any other part of the plant (leaves, $26 \%$; open flowers, $7 \%$; and stems, $1 \%$ ); of the 75 beetles found on leaves, $84 \%$ were on wilted leaves.

Plant growth form (vertical versus horizontal) much more strongly affected beetle abundances than did plant diversity (Table 1), with plants growing vertically averaging a greater number of beetles than those growing horizontally. The significant effect of an interaction between growth form and diversity partially explains the much greater number of beetles in one treatment. In fact, when individual comparisons are made between all types of plots, the only significant differences are that $\mathrm{C}-\mathrm{V}$ plots had significantly more beetles than any other type of plot. From these comparisons, we can conclude that (1) the highly significant growth form effect was primarily caused by differences between vertical and horizontal growth form in monoculture, (2) the greater beetle abundances in monoculture than in plots containing corn or tomatoes was significant only for monocultures with vertical growth form, and (3) beetles did not seem to distinguish between corn and tomatoes.

Greater numbers of beetles in cucumber monocultures with vertical growth form was true not only for totals over the entire season, but also for individual sampling dates (Fig. 1). There did not appear to be any difference in the number of beetles which initially colonized the six treatments (see Fig. 1), nor were there differences in the dates on which beetles colonized the plots. When the first sampling date on which beetles were found for each plot is compared, there are no significant effects of growth form, diversity, or an interaction (two-way ANOVA, Table 2). Thus, the overall differences in total numbers of beetles appear to result from differences in rates of accumulation (subsequent colonization and/or tenure time).

Plant size (as measured by the length of vines) was affected more strongly by diversity and an interaction between growth form and diversity, than by growth form alone (Table 1). Individual comparisons revealed that the only significant differences 
Table 1. Total number of Acalymma vittata over the entire season and length of vines $(\mathrm{cm})$ for plants in the experimental plots $(N=16$ for each treatment) and associated ANOVA results. Means \pm standard deviations are presented, as well as minimum and maximum values (in parentheses). For the analysis of number of beetles. ANOVA tests were performed on $\log$ transformed data to satisfy the equality of variances assumption. $(\mathrm{C}=$ cucumber, $\mathrm{CC}=$ cucumber $/$ corn, $\mathrm{CT}=\mathrm{cu}-$ cumber/tomato)

\begin{tabular}{llll}
\hline Growth Form & Diversity & $\begin{array}{l}\text { Number } \\
\text { of Beetles }\end{array}$ & $\begin{array}{l}\text { Length of Vines } \\
(\mathrm{cm})\end{array}$ \\
\hline Vertical & $\mathrm{C}$ & $\begin{array}{l}9.9 \pm 9.2 \\
(0.32)\end{array}$ & $\begin{array}{l}662.3 \pm 231.8 \\
(221,1050)\end{array}$ \\
Vertical & $\mathrm{CC}$ & $\begin{array}{l}2.9 \pm 2.0 \\
(0.5)\end{array}$ & $\begin{array}{l}262.8 \pm 105.6 \\
(33,430)\end{array}$ \\
Vertical & $\mathrm{CT}$ & $\begin{array}{l}3.0 \pm 2.4 \\
(0,7)\end{array}$ & $\begin{array}{l}457.2 \pm 278.0 \\
(102,1063)\end{array}$ \\
Horizontal & $\mathrm{C}$ & $\begin{array}{l}1.8 \pm 2.8 \\
(0,9)\end{array}$ & $\begin{array}{l}377.6 \pm 278.1 \\
(46,1002)\end{array}$ \\
Horizontal & $\mathrm{CC}$ & $1.0 \pm 1.2$ & $\begin{array}{l}271.4 \pm 121.0 \\
(0,476)\end{array}$ \\
Horizontal & $\mathrm{CT}$ & $\begin{array}{l}(0,3) \\
1.1 \pm 1.0\end{array}$ & $\begin{array}{l}454.4 \pm 285.1 \\
(139,1201)\end{array}$ \\
\hline Effect & $\mathrm{df}$ & $\mathrm{F}$ & $\mathrm{F}$ \\
\hline Growth Form & $(1,72)$ & $34.17^{* *}$ & $5.34^{*}$ \\
Diversity & $(2,72)$ & $4.61^{*}$ & $14.20^{* *}$ \\
Block & $(3,72)$ & 0.40 & 2.26 \\
Interaction & $(2,72)$ & $3.29^{* *}$ & $5.66^{* *}$ \\
\hline
\end{tabular}

$* p<0.05 \quad * * p<0.01$

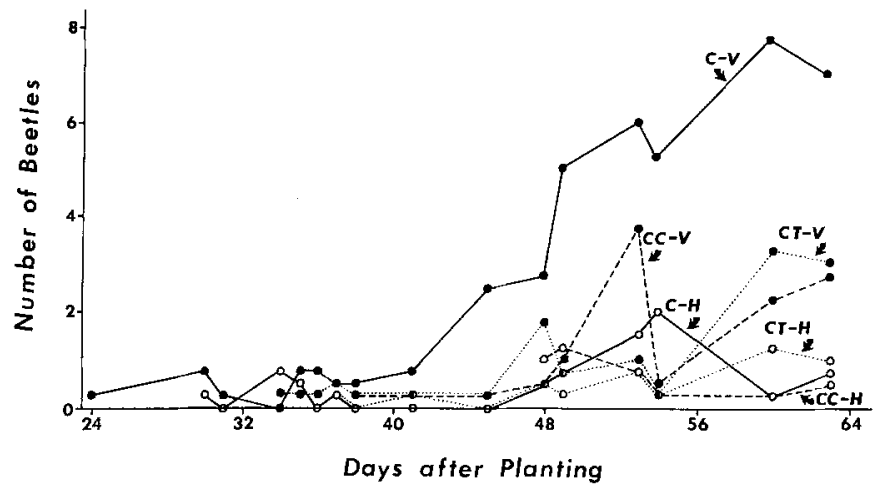

Fig. 1. Mean number of Acalymma vittata in the six types of experimental plots during the season. Plots with vertical growth forms $(V)$ are represented with closed circles and plots with horizontal growth forms $(H)$ with open circles. Plot diversity is represented as: cucumber $(C, \longrightarrow)$ cucumber/corn $(C C, \ldots)$, and cucumber/tomato $(C T, \cdots)$. Means were calculated for four replicate plots for each treatment

were that $\mathrm{C}-\mathrm{V}$ plots had greater lengths of vines than $\mathrm{C}-\mathrm{H}$, $\mathrm{CC}-\mathrm{H}$, or $\mathrm{CC}-\mathrm{V}$ plots. These differences suggest three interesting results: (1) monoculture cucumber plants had larger sizes when grown vertically than when grown horizontally, but growth form did not affect plant size when grown with additional plant species, (2) cucumber plants grown with tomatoes were not significantly smaller than monoculture plants, and (3) again as with beetle abundances, the larger values were obtained only by a combination of vertical growth form and monoculture.

Despite the fact that the largest plants were found in $\mathrm{C}-\mathrm{V}$ plots, two lines of evidence suggest that the greater number of beetles in $\mathrm{C}-\mathrm{V}$ plots was not simply a result of greater plant
Table 2. First sampling date on which plots were colonized by beetles (days after planting) and associated ANOVA results. Means \pm standard deviations for the four replicate plots are presented, as well as minimum and maximum values (in parentheses)

\begin{tabular}{lll}
\hline Growth Form & Diversity & $\begin{array}{l}\text { Date of Initial Colonization } \\
\text { (DAP) }\end{array}$ \\
\cline { 2 - 3 } Vertical & $\mathrm{C}$ & $\begin{array}{l}32.5 \pm 7.2 \\
(24,41)\end{array}$ \\
Vertical & $\mathrm{CC}$ & $\begin{array}{l}46.0 \pm 5.4 \\
(38,49)\end{array}$ \\
Vertical & $\mathrm{CT}$ & $\begin{array}{l}44.2 \pm 12.3 \\
(34,60)\end{array}$ \\
Horizontal & $\mathrm{C}$ & $\begin{array}{l}49.2 \pm 14.6 \\
(30,65)\end{array}$ \\
Horizontal & $\mathrm{CC}$ & $\begin{array}{l}49.5 \pm 3.0 \\
(48,54)\end{array}$ \\
Horizontal & $\mathrm{CT}$ & $46.5 \pm 10.1$ \\
& & $(37,60)$ \\
\hline Effect & $\mathrm{df}$ & $\mathrm{F}$ \\
\hline Growth Form & $(1,18)$ & $3.64 \mathrm{p}>0.05$ \\
Diversity & $(2,18)$ & $1.05 \mathrm{p}>0.05$ \\
Interaction & $(2,18)$ & $1.39 \mathrm{p}>0.05$ \\
\hline
\end{tabular}

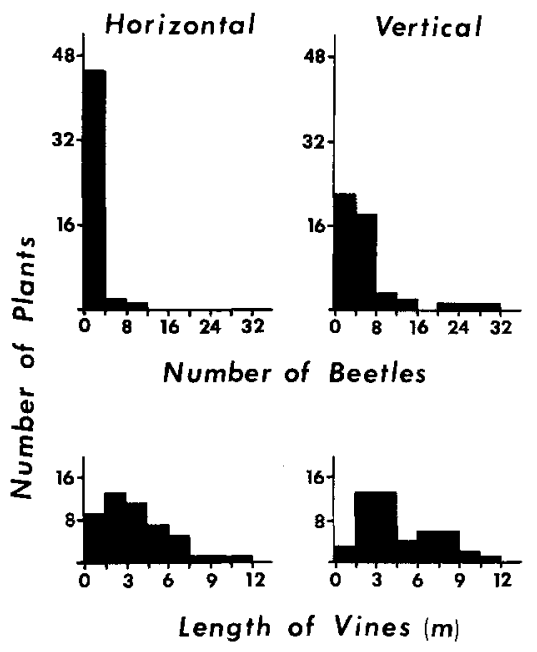

Fig. 2. Frequency distributions of the total number of beetles and length of vines $(m)$ for plants in vertical growth form $(N=48)$ and horizontal growth form plots $(N=48)$

sizes. First, the frequency distributions of vine lengths in vertical and horizontal growth form plots (Fig. 2) are much more similar than are the frequency distributions for numbers of beetles. Secondly, although the correlation between number of beetles and vine length is statistically significant overall $(r=0.30, N=96$, $p<0.01$ ), less than $10 \%$ of the variance in beetle numbers is explained by plant size. Moreover, this correlation is only significant for plants with horizontal growth form $(r=0.47, N=48$, $p<0.01)$, but not for plants with vertical growth form $(r=0.24$, $N=48, p>0.05$ ). Thus, plant size alone can not account for the differences in numbers of beetles caused by diversity or growth form. 


\section{Feeding Preference Experiments}

Beetles given a choice of cucumber leaves from cucumber monocultures (C--V plots) and plots with tomatoes (CT-V plots) displayed a strong preference for leaves from cucumber monocultures, as measured by the number of beetles which consumed a greater amount of one leaf than the other (Table 3). Out of 45 beetles which exhibited a preference, $69 \%$ preferred cucumber monoculture leaves. Moreover, of the 26 beetles which fed exclusively on one leaf, $21(81 \%)$ chose leaves from cucumber monocultures.

However, there was no significant difference in the amount of feeding damage caused by beetles preferring $\mathrm{C}$ leaves and beetles preferring CT leaves (Table 4). This result was true both for beetles feeding exclusively on one leaf and beetles feeding on both leaves. In fact, for those beetles which fed on both leaves, there was no difference in the number exhibiting a preference for $\mathrm{C}$ leaves $(N=10)$ and $\mathrm{CT}$ leaves $(N=9)$. Thus, the greater overall amount of feeding damage to cucumber monoculture leaves was caused by the significantly greater number of beetles choosing that type of leaf, rather than by a greater amount of feeding damage per leaf.

If the strength of feeding preference of individual beetles is measured as the difference in the amounts of damage to the two types of leaves (thus a measure of the relative amount consumed), there were no significant differences in the strengths of preference exhibited by beetles preferring monoculture leaves when compared to beetles preferring leaves from plots with tomatoes (Table 4). Thus, significantly fewer beetles chose leaves from plots with tomatoes, but those beetles caused as much feeding

Table 3. Feeding preferences of beetles in three sets of choice experiments in which beetles were offered two equal-sized cucumber leaves, one from cucumbers grown in monoculture $(\mathrm{C})$ and one from cucumbers grown with tomatoes (CT). Preference was measured as the number of individuals for which there was a $\geqq 0.25 \mathrm{~cm}^{2}$ difference in the amount eaten of the two types of leaves. Numbers in parentheses represent the number of individuals with a particular preference which fed exclusively on one leaf

\begin{tabular}{|c|c|c|c|}
\hline Replicate & Preferred C & Preferred CT & No Preference \\
\hline I & $10 \quad(8)$ & 3 (2) & 7 \\
\hline II & $11 \quad(7)$ & $4 \quad(0)$ & 5 \\
\hline III & $10 \quad(6)$ & 7 (3) & 3 \\
\hline TOTAL & $31 *(21 * *)$ & $14^{*}\left(5^{* *}\right)$ & 15 \\
\hline
\end{tabular}

* sign test; $\mathrm{p}<0.025 \quad$ ** sign test; $\mathrm{p}<0.01$ damage per leaf and exhibited as strong a preference as did those beetles which preferred leaves from cucumber monoculture plots.

\section{Discussion}

This study demonstrates a marked effect of interspecific neighbors on plant quality, as measured by herbivore feeding preference. Although the relationship between plant spatial pattern and plant quality (Fagan et al. 1943, Way and Heathcote 1966) and the relationship between plant quality and herbivore population dynamics (Cates 1980, Morrow and Fox 1980) have been investigated, this study is one of the first to provide evidence for a direct link between plant diversity and herbivore abundance via differences in plant quality. This difference in herbivore preference for host plants grown under different conditions has only been reported in a small number of studies; Lower (1972) and Tahvanainen and Root (1972) found the amount of herbivore feeding damage to be influenced by what species of plants were grown near the host plants, but did not do controlled feeding experiments in the laboratory to assess the role of plant quality. Bach (in preparation) found that Acalymma innuba (Fab.) preferred leaves from cucurbit plants growing in the open over leaves from the same species of plant growing in a forest.

The differences in feeding behavior of the beetles could either result from individual differences among beetles or from variance in plant quality, but could not be due to sun/shade leaf differences since all leaves utilized had been growing in full sunlight. It seems likely that various aspects of plant quality (e.g., moisture content, nitrogen content, etc.) differed simply because plants in monocultures and plants in plots with tomatoes were subjected to different amounts of intra- versus interspecific competition. It is also possible that the cucumber plants grown with tomatoes actually acquired repellent chemicals from the tomato plants (either through the roots or leaves); this inter-plant movement of chemicals has been reported for alkaloids (Winter 1961).

This study also demonstrates that the abundance of a specialist herbivore is strongly affected by the growth form of its host plant and that this effect is even stronger than that caused by plant diversity. Other studies have found differences in herbivore abundances in different sized patches of host plants (Cromartie 1975, Root 1975, Raupp and Denno 1979), different diversity patches (Tahvanainen and Root 1972, Root 1973, Dempster and Coaker 1974, Smith 1976, Altieri et al. 1977, 1978, Bach 1980a, 1980 b), and different density patches (Pimentel 1961, Way and Heathcote 1966, Ralph 1977a, Thompson and Price 1977), but no study has examined (1) effects of horizontally versus vertically growing forms of the same species of host plants

Table 4. Amount of feeding damage to preferred leaf and strength of feeding preference for beetles preferring $\mathrm{C}$ and beetles preferring $\mathrm{CT}$ leaves in choice experiments (described in caption to Table 3 ). Strength of preference was measured as the difference in the amounts eaten of the two leaves

\begin{tabular}{|c|c|c|c|c|c|c|c|c|}
\hline & \multicolumn{3}{|c|}{ Beetles preferring $\mathrm{C}$} & \multicolumn{3}{|c|}{ Beetles preferring CT } & \multicolumn{2}{|c|}{ Mann-Whitney U test } \\
\hline & $N$ & $\bar{x}$ & s.d. & $N$ & $\bar{x}$ & s.d. & $T$ & $p$ \\
\hline \multicolumn{9}{|l|}{ Both leaves fed upon } \\
\hline Amount eaten $\left(\mathrm{cm}^{2}\right)$ & 10 & 1.35 & 0.78 & 9 & 0.94 & 0.48 & 75.5 & $\mathrm{p}>0.05$ \\
\hline $\begin{array}{l}\text { Strength of } \\
\text { preference }\left(\mathrm{cm}^{2}\right)\end{array}$ & 10 & 0.80 & 0.59 & 9 & 0.53 & 0.29 & 78.5 & $p>0.05$ \\
\hline \multicolumn{9}{|l|}{ One leaf fed upon } \\
\hline Amount eaten $\left(\mathrm{cm}^{2}\right)$ & 21 & 1.15 & 0.73 & 5 & 1.05 & 0.65 & 67 & $p>0.05$ \\
\hline
\end{tabular}


or (2) host plants growing near versus growing intertwined with another species. It certainly appears that it is not simply structural effects of additional plant species in polycultures which lead to reduced numbers of herbivores, since (1) cucumber monocultures with increased structure (i.e., vertical growth forms) had increased beetle numbers when compared to plots with the same species composition with less structure (horizontal growth forms), and (2) there were no differences in beetle numbers between mixed species plots which had additional plant species with different structures (corn and tomatoes).

While many factors might contribute to the greater number of beetles on plants growing vertically than on plants growing horizontally (including differences in microclimatic conditions), it appears that beetle flight patterns are one of the causal mechanisms. Observations on the flight patterns of a closely related species, Acalymma innuba, revealed that the majority of beetles fly upwards when disturbed (Bach in preparation), thus accumulating on plants growing vertically rather than on plants growing horizontally (i.e., on the ground).

The lack of a difference in beetle abundance on vertically and horizontally growing cucumbers when interplanted with corn or tomatoes emphasizes the interaction between plant growth form and other variables such as plant diversity, in influencing herbivore populations. It does not appear that cucumbers growing up other plant species mask the effects of these other species thus making the plot appear more like a monoculture. This finding is consistent with other studies of this herbivore/plant system which suggest that beetle numbers are not determined by visual or chemical responses of beetles from outside plots but are influenced by behavior once beetles are in a plot (Bach 1980a, 1980 b).

The majority of studies comparing abundances of specialist herbivores in different diversity habitats (Tahvanainen and Root 1972, Root 1973, Dempster and Coaker 1974, Smith 1976, Altieri et al. 1977, 1978), including studies of $A$. vittata on cucumbers (Bach 1980a, 1980b), have found greater herbivore abundances in monocultures of host plants than in more diverse plots. Results from this study show that host plant growth form can reverse this trend; horizontally growing cucumbers in monoculture did not have greater numbers of beetles than either vertical or horizontal plants in polyculture. Only for monocultures with vertically growing plants were numbers greater than in polycultures, again emphasizing the interaction between growth form and diversity.

There is support for two causal mechanisms (involving plant quality and movement patterns) to explain these differences in abundance caused by diversity. It appears from the results of the laboratory feeding experiments reported in this study that (1) plant quality (as measured by herbivore preference) differs for cucumbers grown in monoculture and with additional plant species, (2) this difference in quality leads to feeding preferences for cucumber monoculture leaves, and (3) this preference may account at least partially for the observed higher beetle abundances in cucumber monocultures than in polycultures. It would be interesting to compare feeding preferences for leaves from plants grown with corn and plants grown with tomatoes, to clarify the result that beetles did not appear to distinguish between plots with corn and plots with tomatoes (since a difference had been expected based on both chemical and structural differences between corn and tomatoes).

The second mechanism contributing to higher herbivore abundances in monocultures involves the tenure time of beetles on host and non-host plants. Although it has been shown that insects remain for longer periods of time in large patches of host plants than in small patches (Ralph 1977b) and longer in monocultures than in more diverse polycultures (Bach 1980a, $1980 \mathrm{~b}$ ), the mechanism(s) has not been documented. Bach (in preparation) found that beetles (Acalymma innuba) appeared to land randomly on host and non-host plants, but remained for significantly longer periods of time on host plants. Thus, at least one mechanism for the reported differences in movement patterns seems to involve higher emigration rates from non-host plants.

Most studies comparing the population dynamics of specialist herbivores in monocultures of their host plant and in polycultures containing additional plant species have not taken plant growth form into account. In all studies for which growth form is reported, the host plants are not growing vertically up other plants in polycultures (Tahvanainen and Root 1972, Dempster and Coaker 1974, Altieri et al. 1977, 1978, Risch 1979, Bach $1980 \mathrm{a}, 1980 \mathrm{~b}$ ). This study strongly suggests that very different results (i.e., less of a difference between monoculture and polyculture) would be obtained if the host plants in polycultures had a vertical growth form. Certainly, the comparisons drawn between agricultural and natural plant communities regarding the interaction between plant spatial pattern and herbivore population dynamics need to take this factor into account.

This study reports a distinct response by a specialist herbivore to extremely small experimental plots, as well as unique results regarding both effects of growth form on herbivore abundances and effects of diversity on plant quality, as measured by herbivore feeding preference for its host plant. Unfortunately, it is not possible to determine whether the lack of similar findings for other herbivore/plant systems is because other studies have not been done or because they have been done but obtained negative results. The important implications of these results to both theoretical ecology and applied areas such as insect pest management strongly suggest a profitable direction for future work in specialist herbivore/host plant interactions.

Acknowledgements. This research was supported by a Dr. Chaim Weizmann Postdoctoral Fellowship. I thank the Matthaei Botanical Gardens (University of Michigan) and the Michigan NWAG (New World Agriculture Group) for providing and preparing the land. Brian Hazlett, Beverly Rathcke, Peter Rosset, and John Vandermeer critically commented on the manuscript.

\section{References}

Altieri MA, van Schoonhoven A, Doll J (1977) The ecological role of weeds in insect pest management systems: a review illustrated by bean (Phaseolus vulgaris) cropping systems. PANS 23:195-205

Altieri MA, Francis CA, van Schoonhoven A, Doll JD (1978) A review of insect prevalence in maize (Zea mays L.) and bean (Phaseolus vulgaris L.) polycultural systems. Field Crop Res 1:33-49

Bach CE (1980a) Effects of plant diversity and time of colonization on an herbivore-plant interaction. Oecologia (Berl) 44:319-326

Bach CE (1980 b) Effects of plant density and diversity on the population dynamics of a specialist herbivore, the striped cucumber beetle, Acalymma vittata (Fab.). Ecology $61: 1515-1530$

Bach CE, Hruska AJ (1981) Effects of plant density on the growth, reproduction and survivorship of cucumbers (Cucumis sativus L.) in monocultures and polycultures. J Appl Ecol: In Press

Brown JJ, Jermy $T$, Butt BA (1980) The influence of an alternate host plant on the fecundity of the colorado potato beetle, Leptinotarsa decemlineata (Coleopotera: Chrysomelidae). Ann Entomol Soc Am 73:197-199

Cates RG (1980) Feeding patterns of monophagous, oligophagous, and polyphagous insect herbivores: the effect of resource abundance and plant chemistry. Oecologia (Berl) 46:22-31 
Chiang HC, Flaskard RG (1965) Sampling methods of adult populations of the corn rootworm. Proc N Cent Br Ent Soc Am 20:67-68

Chew FS (1980) Food plant preferences of Pieris caterpillars (Lepidoptera). Oecologia (Berl) 46:347-353

Cromartie WJ (1975) The effect of stand size and vegetational background on the colonization of cruciferous plants by herbivorous insects. J Appl Ecol 12:517-533

Dempster JP, Coaker TH (1974) Diversification of crop ecosystems as a means of controlling pests. In : DP Jones, ME Solomon (eds), Biology in pest and disease control, Blackwell Sci Pub London p 106-114

Fagan TW, Phillips R, Davies RO (1943) The cultivation and composition of kale. Welsh Jour Agric 17:97-101

Hsiao TH, Fraenkel G (1968) Selection and specificity of the colorado potato beetle for solanaceous and nonsolanaceous plants. Ann Entomol Soc Am 61:493-503

Lower RL (1972) Effect of surrounding cultivar when screening cucumber for resistance to cucumber beetle and pickleworm. J Amer Soc Hort Sci 97:616-618

Lawton JH (19.78) Host-plant influences on insect diversity: the effect of space and time. In: LA Mound, N Waloff (eds), Diversity of insect faunas, RES Symp 9 Blackwell Sci Pub Oxford p 105-125

Mattson WJ (1980) Herbivory in relation to plant nitrogen content. Ann Rev Ecol Syst 11:119-161

McNeill S, Southwood TRE (1978) The role of nitrogen in the development of insect/plant relationships. In: JB Harborne (ed), Biochemical aspects of plant and animal coevolution, Proc Phytochem Soc 15 Academic Press New York-London p 77-98

Morrow PA, Fox LR (1980) Effects of variation in Eucalyptus essential oil yield on insect growth and grazing damage. Oecologia (Berl) 45:209-219

Murdoch WM, Evans FC, Peterson CH (1972) Diversity and pattern in plants and insects. Ecology 53:819-829

Pimentel D (1961) The influence of plant spatial patterns on insect populations. Ann Ent Soc Am 54:61-69

Ralph CP (1976) Natural food requirements of the large milkweed bug, Oncopeltus fasciatus (Hemiptera: Lygaeidae), and their relation to gregariousness and host plant morphology. Oecologia (Berl) $26: 157-175$

Ralph CP (1977a) Effect of host plant density on populations of a specialized seed-sucking bug, Oncopeltus fasciatus. Ecology $58: 799-809$

Ralph CP (1977b) Search behavior of the large milkweed bug, Oncopeltus fasciatus (Hemiptera: Lygaeidae). Ann Ent Soc Am 70:337-342
Raupp MJ, Denno RF (1979) The influence of patch size on a guild of sap-feeding insects that inhabit the salt marsh grass Spartina patens. Environ Entomol 8:412 417

Risch SJ (1979) A comparison, by sweep sampling, of the insect fauna from corn and sweet potato monocultures and dicultures in Costa Rica. Oecologia (Berl) 42:195-211

Root RB (1973) Organization of a plant-arthropod association in simple and diverse habitats: the fauna of collards (Brassica oleracea). Ecol Monographs 43:95-124

Scriber JM, Feeny P (1979) Growth of herbivorous caterpillars in relation to feeding specialization and to the growth form of their food plants. Ecology $60: 829-850$

Slansky F, Feeny P (1977) Stabilization of the rate of nitrogen accumulation by larvae of the cabbage butterfly on wild and cultivated food plants. Ecol Monographs 47:209-228

Smith JG (1976) Influence of crop background on aphids and other phytophagous insects on brussel sprouts. Ann Appl Biol 83:1-13

Smith RW, Whittaker JB (1980a) The influence of habitat type on the population dynamics of Gastrophysa viridula DeGeer (Coleoptera: Chrysomelidae). J Anim Ecol 49:225-236

Smith JW, Whittaker JB (1980b) Factors affecting Gastrophysa viridula populations (Coleoptera: Chrysomelidae) in different habitats. I Anim Ecol 49:537-548

Tahvanainen JO, Root RB (1972) The influence of vegetational diversity on the population ecology of a specialized herbivore, Phyllotreta cruciferae (Coleoptera: Chrysomelidae). Oecologia (Berl) $10: 321-346$

Thompson JN, Price PW (1977) Plant plasticity, phenology, and herbivore dispersion: wild parsnip and the parsnip webworm. Ecology $58: 1112-1119$

van Emden HF (1965) The effect of uncultivated land on the distribution of cabbage aphid on an adjacent crop. J Appl Ecol 2:171196

Way MJ, Heathcote GD (1966) Interactions of crop density of field beans, abundance of Aphis fabae Scop., virus incidence and aphid control by chemicals. Ann Appl Biol 57:409-423

Winter AG (1961) New physiological and biological aspects in the interrelationships between higher plants. In: FL Milthorpe (ed), Mechanisms in biological competition, Symp Soc Exp Biol 15 Academic Press New York-London p 229-244

Received January 26, 1981 